\title{
GENETIC VARIATION IN ANTIOXIDANT ENZYMES AND LUNG FUNCTION
}

\author{
Amy R. Bentley ${ }^{1,2}$, Stephen B. Kritchevsky ${ }^{3}$, Tamara B. Harris ${ }^{4}$, Anne B. Newman ${ }^{5}$, \\ Douglas C. Bauer ${ }^{6}$, Bernd Meibohm ${ }^{7}$, Andrew G. Clark ${ }^{8}$, and Patricia A. Cassano ${ }^{2}$ for the \\ Health ABC Study \\ ${ }^{1}$ Center for Research in Genomics and Global Health, National Human Genome Research \\ Institute, Bethesda, MD \\ ${ }^{2}$ Division of Nutritional Sciences, Cornell University, Ithaca, NY \\ ${ }^{3}$ Sticht Center on Aging, Wake Forest School of Medicine, Winston-Salem, NC \\ ${ }^{4}$ Intramural Research Program, National Institute on Aging, Bethesda, MD \\ ${ }^{5}$ Center for Aging and Population Health, University of Pittsburgh, PA \\ ${ }^{6}$ Departments of Medicine and Epidemiology \& Biostatistics, University of California San \\ Francisco, San Francisco, CA \\ ${ }^{7}$ University of Tennessee, Memphis, TN \\ ${ }^{8}$ Department of Molecular Biology and Genetics, Cornell University, Ithaca NY
}

\section{Abstract}

\begin{abstract}
Not all cigarette smokers develop chronic obstructive pulmonary disease (COPD), and discovering susceptibility factors is an important research priority. The oxidative burden of smoking may overwhelm antioxidant defenses, and vulnerabilities may exist as a result of sequence variants in genes encoding antioxidant enzymes. This study explored the association between genetic variation in a network of antioxidant enzymes and lung phenotypes. Linear models evaluated single locus marker associations in 2,387 European and African American participants in the Health, Aging, and Body Composition (Health ABC) Study. After correcting for multiple comparisons, 15 statistically significant associations were identified, all of which were for SNP by smoking interactions. The most statistically significant findings were in genes encoding members of the isocitrate dehydrogenase gene family (IDH3A, IDH3B, IDH2). For rs6107100 (IDH3B) the variant genotype was associated with a difference of $6 \%$ in the $\mathrm{FEV}_{1} / \mathrm{FVC}$ ratio in African American current smokers, but the SNP had little or no association with $\mathrm{FEV}_{1} / \mathrm{FVC}$ in former and never smokers (nominal $\left.p_{\text {interaction }}=5 \times 10^{-6}\right)$. A variant in peroxiredoxin gene $(\mathrm{rs} 9787810$, $P R D X 5$ ) was associated with lower \%predicted $\mathrm{FEV}_{1}$ and a lower ratio in European American current smokers, with little or no association in other smoking groups (nominal $p_{\text {interaction }}=0.0001$ and 0.0003 , respectively). The studied genes have not been reported in previous candidate gene
\end{abstract}

C 2012 Elsevier Inc. All rights reserved.

CORRESPONDING AUTHOR: Patricia A. Cassano, Division of Nutritional Sciences, 209 Savage Hall, Cornell University, Ithaca, NY 14853; pac6@cornell.edu; Phone: 607-255-7551; Fax: 607-255-2691.

Publisher's Disclaimer: This is a PDF file of an unedited manuscript that has been accepted for publication. As a service to our customers we are providing this early version of the manuscript. The manuscript will undergo copyediting, typesetting, and review of the resulting proof before it is published in its final citable form. Please note that during the production process errors may be discovered which could affect the content, and all legal disclaimers that apply to the journal pertain.

Author disclosure: AR Bentley, S Kritchevsky, T Harris, A Newman, DC Bauer, B Meibohm, A Clark and PA Cassano have no conflicts of interest 
association studies, and thus the findings suggest novel mechanisms and targets for future research, and provide evidence for a contribution of sequence variation in genes encoding antioxidant enzymes to susceptibility in smokers.

\section{Keywords}

Antioxidant enzymes; Lung function

\section{Introduction}

Chronic obstructive pulmonary disease (COPD) is characterized by the development of airflow obstruction that is not fully reversible, a phenotype that is characteristic of chronic bronchitis and emphysema. At advanced stages, COPD progresses to respiratory failure and death, and is a significant cause of morbidity as well as the fourth leading cause of mortality in the U.S.[1]. Spirometry is a reliable and valid means of identifying airflow obstruction; clinical definitions of COPD [2] are based on the ratio of air exhaled in the first second of effort/total air exhaled (Forced Expiratory Volume in the $1^{\text {st }}$ second/Forced Vital Capacity: $\mathrm{FEV}_{1} / \mathrm{FVC}$ ) and the absolute level of $\mathrm{FEV}_{1}$ compared to what would be predicted given age, height, race, and gender (percent predicted $\mathrm{FEV}_{1}: \mathrm{ppFEV}_{1}$ ). Decline in $\mathrm{FEV}_{1}$ occurs naturally with aging, but a steeper rate of decline, as observed in susceptible cigarette smokers, is a harbinger of the debilitating low lung function that characterizes COPD.

Current theories of the pathogenesis of COPD posit that an imbalance between oxidant burden and antioxidant protection leads to oxidative damage that contributes to disease pathogenesis. Diminished antioxidant defenses, especially among cigarette smokers, who are exposed to a high level of oxidants, are hypothesized to contribute to tissue changes underlying disease development [3]. A minority of smokers develop obstructive lung disease [4], consistent with the hypothesis that in some smokers compromised antioxidant protection, as a result of genetic variation in antioxidant enzymes, diets low in antioxidants, and/or inflammation, contributes to susceptibility. While observational studies mainly report positive associations between nutrients with antioxidant properties and lung function, with stronger effects in cigarette smokers, studies of genes that play a role in antioxidant defenses provide an important and unique test of the susceptibility hypothesis.

Lung function is a heritable trait, and heritability estimates of $\mathrm{FEV}_{1}$ and the ratio of $\mathrm{FEV}_{1}$ / FVC range from 40-90\% [5-7]. A single gene disorder that increases COPD risk, alpha 1antitrypsin deficiency, accounts for only about 1 to $2 \%$ of cases [8], confirming the importance of additional genes and gene $\times$ environment interactions in lung function variability. Recently completed genome-wide association studies of lung function phenotypes [9-11] have identified 14 genomic regions for further investigation. Welldesigned studies of candidate genes, specifically of genes encoding antioxidant enzymes, are important to the evidence base, but published studies have several limitations (as reviewed in [12]). The majority of studies considered only a few markers and/or genes, and thus do not capture the related and redundant functions within the network of antioxidant-related genes. Published studies focus on a limited subset of genes (most prominently, glutathione S-transferases), thus many genes related to antioxidant defense are unstudied at the population level (for example, genes of the thioredoxin system: thioredoxin, thioredoxin reductase, and peroxiredoxin). Studies of the heritability of lung function provide compelling evidence for a gene-environment interaction [13-15], specifically a gene by smoking interaction, and a recent genome-wide assessment of gene expression in the small airway epithelium and genotype in smokers and non-smokers indicates that smoking modifies the relation between genotype and gene expression (Mezey J personal 
communication). Despite this evidence, most studies do not consider gene-environment interactions and/or do not appropriately account for cigarette smoking in study design and analysis. Finally, data on African Americans are limited, and most studies with African American participants are underpowered to investigate any differences in the effects of genotype on lung phenotype by race.

We investigated the association of variants in genes encoding antioxidant enzymes with the lung function phenotypes $\mathrm{ppFEV}_{1}$ and $\mathrm{FEV}_{1} / \mathrm{FVC}$. As the elderly are at the greatest risk for reduced lung function associated both with aging and smoking, these analyses were conducted in the Health, Aging, and Body Composition (Health ABC) Study. While the Health $\mathrm{ABC}$ is a prospective cohort, this analysis is cross-sectional, evaluating study data collected at baseline. The analysis explored the relation of all genotypes with the two phenotypes, stratified by race, and allowing for differential effects of genotype by cigarette smoke exposure and dose.

\section{Methods}

\section{Population}

The Health ABC cohort study enrolled 3,075 men and women aged 70-79 at the study baseline in 1997. Health ABC is a random sample of European Americans and African American Medicare-eligible persons residing in ZIP codes from the metropolitan areas surrounding Pittsburgh, Pennsylvania and Memphis, Tennessee. Eligibility criteria included self-report of: no difficulty walking one-quarter of a mile or climbing 10 steps without resting; no difficulty performing basic activities of daily living; no use of a cane, walker, crutches or other special equipment to ambulate; no history of active treatment for cancer in the prior 3 years; and no plan to move out of the area in the subsequent 3 years.

Exclusion criteria included a low call rate for genotypes (i.e. if the classification of genotype was unsuccessful in $>5 \%$ of samples), missing outcome measurements, or prevalent chronic obstructive pulmonary disease, defined as both $\mathrm{FEV}_{1}$ and $\mathrm{FEV}_{1} / \mathrm{FVC}$ below the populationdefined lower limits of normal. Prevalent COPD cases were excluded as our interest was on genetic susceptibility to low lung function, not to disease progression. Exclusions were also made based on quality of spirometry testing for $\mathrm{FEV}_{1}$; participants with low quality $\mathrm{FVC}$ measurements were further excluded from the $\mathrm{FEV}_{1} / \mathrm{FVC}$ analysis.

\section{Lung Function Outcome}

Spirometry was performed during the clinical visit at study entry using a horizontal dry rolling seal HF6 Spirometer (Sensor Medics Corporation, Yorba Linda, CA) connected to a personal computer. Tests were conducted in accordance with ATS standardized guidelines, as previously reported [16]. $\mathrm{PpFEV}_{1}$ values were calculated using race-specific prediction equations generated from the Third National Health and Nutrition Examination Survey data [17]. If baseline pulmonary function measurements were missing (or did not meet quality control standards), a measurement from a subsequent clinical visit was substituted, if available, provided that the age of the participant at the available measurement was between 70 and 79 years (the age range of the sample at baseline). The majority (95\%) of data used in these analyses were from the first clinic visit.

\section{Selection of SNPs}

Fifty-six genes were identified that are known to affect the balance of antioxidants/oxidants and are expressed in lung tissue (Supplemental Table 1); briefly, selected genes encoded the following: glutathione synthesis proteins, glutathione S-transferases, peroxidases, hemeoxygenases, disulfide reductases, selenoproteins, proteins affecting supply of reducing 
equivalents, superoxide dismutases, and catalase. 384 single nucleotide polymorphisms (SNPs) were selected with the goal of capturing sequence variation across each gene and its regulatory region (2 kb upstream and downstream). SNP selection was conducted according to the following order of priority: 1. nonsynonymous SNPs, which alter the sequence of encoded proteins (and have an increased probability of functional effects) 2. SNPs to cover variation across the gene by evaluating the degree of correlation (linkage disequilibrium: LD) between SNPs (a maximum of 0.9 LD units between SNPs was allowed), 3. if genetic variation was limited across the gene, SNPs to cover large physical distance, and 4. SNPs that were highly correlated with SNPs of particular interest to provide redundancy in case of assay failure. When possible, a minimum of 5 SNPs were selected per gene. Separate consideration was given to European American and African Americans in SNP selection to maximize coverage in both populations, given differences in LD structure and allele frequencies. Further details of analyzed SNPs are presented separately (Supplemental Table 2).

\section{Genotyping}

DNA for the Health ABC participants was extracted using the Gentra Puregene DNA Purification Kit (QIAGEN, Valencia, CA) from stored, frozen buffy coat originally extracted from $10 \mathrm{ml}$ whole blood. SNPs were assayed using the Illumina Goldengate platform; genotyping services were provided by Johns Hopkins University under U.S. Federal Government contract number N01-HV-48195 from the National Heart, Lung, and Blood Institute. Genotyping quality was excellent as determined through use of blind duplicates and HapMap controls with known genotypes (99.99\% and $99.83 \%$ reproducibility rates, respectively).

\section{Statistical Analysis}

Linear models were used to evaluate the association between single locus markers and lung function phenotype. Given the probability of confounding by race, as both genotype frequencies and lung function measures differ by race, all analyses were conducted separately in European and African Americans. All models were adjusted for study site, age, height, and gender (for the importance of adjusting $\mathrm{ppFEV}_{1}$ despite the use of age, gender, and height in prediction equations, see [18]). To correct for any population stratification within race groups, all models were also adjusted for principal components of the genotypes (computed separately for European and African American subgroups). SNPs were coded as additive, recessive, dominant, or overdominant, depending on the pattern of association observed and a sufficient number of participants in subgroups of genotype and smoking parameters. SNPs with a minor allele frequency $<1 \%$ were excluded from the analyses ( $\mathrm{n}=29$ SNPs in European Americans; $\mathrm{n}=1$ in African Americans).

Smoking status was represented as current smoker, former smoker, and never smoker (defined as self-report of less than 100 cigarettes smoked throughout lifetime). Lifetime smoking dose was quantified as pack-years, and categorized as high (above the median, 27 packyears), low (1-27 packyears), or no smoking history. Modification of the SNPphenotype association by smoking was assessed through product terms for each SNP with lifetime smoking dose and, separately, through product terms with smoking status.

False Discovery Rate (FDR) adjustment was used to account for multiple comparisons, with a q-value significance threshold of 0.05 [19]. The degree of correlation between SNPs were determined using Haploview [20]. All data analyses were conducted using SAS v 9.1 (SAS, Cary, NC). The Health ABC study was approved by the Institutional Review Boards of the University of Pittsburgh and the University of Tennessee; this study was approved by the Institutional Review Board at Cornell University. 


\section{Results}

Genotype data were available for 2,762 participants. After exclusion for missing smoking information $(\mathrm{n}=5), 2,387(86 \%)$ participants had an acceptable $\mathrm{FEV}_{1}$ measurement and were included in the $\mathrm{ppFEV}_{1}$ analysis, and 2,190 (79\%) also had acceptable FVC measurements and were included in the $\mathrm{FEV}_{1} / \mathrm{FVC}$ ratio analysis (Table 1). Of these, approximately $40 \%$ were African Americans ( $\mathrm{n}=975$ for $\mathrm{ppFEV}_{1}$ and $\mathrm{n}=855$ for $\mathrm{FEV}_{1} / \mathrm{FVC}$ ). A much higher proportion of African Americans were current smokers ( 14\% vs. 5\% of European Americans), and the proportion of former smokers was higher in European Americans (50\% vs. $40 \%$ in African Americans). The mean $\mathrm{ppFEV}_{1}$ was $97 \%$ in this population, with a range of $36 \%$ to $181 \%$ and a standard deviation of $19 \%$. The mean ratio of $\mathrm{FEV}_{1} / \mathrm{FVC}$ (calculated as $\mathrm{FEV}_{1} / \mathrm{FVC} * 100$ ) was $75 \%$, with a range of 34 to 98 and a standard deviation of 6 .

Without consideration of smoking parameters, no SNP had a statistically significant association with either phenotype after False Discovery Rate (FDR) adjustment for multiple comparisons. Fifteen SNP $\times$ smoking interactions were statistically significant at FDR thresholds of statistical significance (Table 2). Of these 15 SNPs, 4 (27\%) were associated with lung phenotypes in European Americans. The majority of observed SNP $\times$ smoking interactions were associated with the $\mathrm{FEV}_{1} / \mathrm{FVC}$ ratio; only two $\mathrm{SNP} \times$ smoking interactions (13\% of findings) were associated with the $\mathrm{ppFEV}_{1}$ phenotype. No SNP $\times$ smoking interaction was statistically significant in both European and African Americans, nor were SNPs in the same gene statistically significant in both ancestry groups. Only one SNP modified the association between smoking and both pulmonary function phenotypes: rs9787810 (PRDX5) in European Americans. Three SNPs modified the association of both smoking status and smoking dose with lung function: rs9787810 (PRDX5) in European Americans, and rs6107100 (IDH3B) and rs2042286 (SEPWI) in African Americans. The largest effect size was $18 \%$ for the ppFEV $_{1}$ phenotype (rs9787810 $\times$ smoking dose in European Americans), and $11 \%$ for the $\mathrm{FEV}_{1} / \mathrm{FVC}$ ratio phenotype (rs $2250192 \times$ smoking dose in African Americans). The proportion of variability explained by the SNP $\times$ smoking interactions varied widely depending on the ancestry group and the phenotype. The PRDX5 rs $9787810 \times$ smoking interaction (the only statistically significant interaction for this phenotype, and significant for both dose and status) accounted for $1 \%$ of the variability in $\mathrm{ppFEV}_{1}$ in European Americans. For the $\mathrm{FEV}_{1} / \mathrm{FVC}$ ratio phenotype, simultaneous models including all statistically significant SNP $\times$ smoking interactions accounted for $3 \%$ and $16 \%$ of the variability in the phenotype in European Americans and African Americans, respectively.

A SNP in the gene encoding the peroxiredoxin PRDX5 (rs9787810) was the most statistically significant finding in several analyses; this SNP modified the association of smoking status with both $\mathrm{ppFEV}_{1}$ and $\mathrm{FEV}_{1} / \mathrm{FVC}$ in European Americans, and modified the association of smoking dose with $\mathrm{ppFEV}_{1}$ (for the $\mathrm{FEV}_{1} / \mathrm{FVC}$ phenotype, the $\mathrm{SNP} \times$ dose term had an adjusted $\mathrm{p}=0.054)$. Notably, this SNP also had borderline statistically significant associations with the $\mathrm{FEV}_{1} / \mathrm{FVC}$ ratio in African Americans ( $\mathrm{p}_{\text {adjusted }}=0.059$ for $\mathrm{SNP} \times$ smoking status; $p_{\text {adjusted }}=0.09$ for SNP $\times$ smoking dose). This SNP showed no evidence of a main effect in either population for either phenotype (in models of the SNP alone, all padjusted $>0.35$ ).

The associations of SNPs in the isocitrate dehydrogenase (IDH) genes with lung function phenotypes were among the most statistically significant findings. Three IDHSNPs in African Americans (all with LD <0.6) and $1 I D H$ SNP in European Americans modified the association between smoking and lung phenotypes. The most statistically significant finding in the analysis was the interaction of $\operatorname{rs} 6107100(I D H 3 B)$ and smoking status in relation to the $\mathrm{FEV}_{1} / \mathrm{FVC}$ ratio $\left(\mathrm{p}_{\text {nominal }}=5 \times 10^{-6}\right)$. In all, 9 of the 15 SNPs in $I D H 3 A, I D H 3 B$, and 
$I D H 3 G$ were associated with lung outcomes after correction for multiple comparisons: 4 of $5 I D H 3 A$ SNPs, 2 of $4 I D H 3 B$ SNPs, and 3 of $6 I D H 3 G$ SNPs, a $4^{\text {th }}$ SNP in this gene was marginally significant, with $p_{\text {adjusted }}=0.053$ [some of these associations do not appear in Table 3 due to small numbers within cells (see below)].

When participant numbers were small ( $\mathrm{n}<5$ within genotype/smoking subgroup), results were excluded from further discussion regardless of statistical significance. Despite the reduced confidence in these results, the strength of the associations observed may suggest a biologically interesting relation; these results are summarized separately (Supplemental Table 3). Briefly, SNPs in genes associated with glutathione synthesis (GCLC and GGT1) and encoding glutathione S-transferases (GSTA3, GSTA5, GSTZ1, and $m G S T 2$ ) were associated with the lung function phenotypes studied. An additional 6 SNPs in $I D H$ genes were associated with lung phenotypes among European Americans, supporting the importance of this family of genes, as presented above.

\section{Discussion}

This study was designed to evaluate the hypothesis that sequence variation in genes encoding antioxidant enzymes, which is expected to alter antioxidant defenses, contributes to COPD susceptibility, especially in cigarette smokers. The findings reported here support this hypothesis and provide important directions for future research.

\section{Peroxiredoxins}

A SNP in the peroxiredoxin family of genes was among the most statistically significant associations. Interactions between a SNP in PRDX5 (rs9787810) and smoking parameters were associated with both lung function phenotypes in European Americans, and a similar interaction between this SNP and smoking dose in predicting the $\mathrm{FEV}_{1} / \mathrm{FVC}$ ratio was of borderline significance. Both the size of the effect (in current smokers, about 8-18\% lower $\mathrm{ppFEV}_{1}$ and a difference of $3 \%$ in $\mathrm{FEV}_{1} / \mathrm{FVC}$ in the $\mathrm{AA} / \mathrm{AG}$ genotype groups vs. wild-type) and the prevalence of the variant genotypes in the European ancestry group (54\%) suggest that this finding is important in terms of population attributable risk. Although these genotypes are less prevalent in African Americans (13\%), the same associations were observed for the $\mathrm{FEV}_{1} / \mathrm{FVC}$ ratio: current smokers with the variant had a $9 \%$ lower ratio ( $\mathrm{p}_{\text {adjusted }}=0.059$ ), and current smokers with a high smoking dose had a $13 \%$ lower ratio, while those with a low dose had a 5\% lower ratio ( padjusted $=0.09$ ). No effect was observed in former or never smokers. In African Americans, a borderline statistically significant interaction between a SNP in another peroxiredoxin gene, PRDX4 (rs528960) and smoking status was also observed.

Peroxiredoxins, also called thioredoxin reductases, are a family of peroxidases that use the reducing power of thioredoxin (with the exception of PRDX6, which uses glutathione). Although, this is the first study of genetic variants in these genes and lung phenotypes, the expression of both $P R D X 3$ and $P R D X 5$ was down-regulated in smokers compared to never smokers [21]. In $P R D X 3$ knockout mice, excessive production of reactive oxygen species (ROS) from macrophages was observed after exposure to lipopolysaccharide, an inflammatory agent from gram-negative bacteria [22]. Further study of peroxiredoxins and COPD-related lung outcomes is warranted.

\section{Isocitrate Dehydrogenases}

Members of the isocitrate dehydrogenase gene family $(I D H)$ were also among the most statistically significant associations, and SNPs in these genes interacted with smoking to predict $\mathrm{FEV}_{1} / \mathrm{FVC}$ in both African Americans and European Americans. The effect sizes for 
SNPs in these genes were large, and most differences between the variant and reference genotypes were $\geq 4 \%$ for the ratio of $\mathrm{FEV}_{1} / \mathrm{FVC}$ for $I D H 3 A, I D H 3 B, I D H 3 G$, and $I D H 2$. The majority of these SNPs are common, minor allele frequencies range from 28 to $44 \%$, thus the potential impact on lung function in smokers is of public health interest. While these genes are relatively unstudied at the population level as contributors to antioxidant defenses, the role they play in supplying the reducing equivalents for the antioxidant activity of the many members of the glutathione and thioredoxin system could be pivotal in determining cellular redox balance. In rats, IDH activity and protein expression was agedependent [23], a finding of interest in relation to the associations reported here for phenotypes related to the aging of the lung. In fibroblasts, decreased expression of $I D H$ genes led to higher lipid peroxidation, oxidative DNA damage, intracellular peroxide generation, and increased senescence, indicating an important regulatory role for these genes in the defense against oxidative stress [24].

\section{Variance in the Functional Outcome Explained by Genotypes}

The most statistically significant SNPs, and their interaction with smoking parameters, accounted for a relatively large proportion of variability in the phenotype. Age, height, gender, principal components, and study site together explained 5\% and 16\% (European and African Americans, respectively) of the $\mathrm{ppFEV}_{1}$ phenotype, and 2\% and 3\% (European and African Americans, respectively) of the $\mathrm{FEV}_{1} / \mathrm{FVC}$ ratio phenotype. Smoking variables explained an additional 4-7 \% of both phenotypes in both European and African Americans. In the context of these known predictors of lung function, the finding that up to $16 \%$ of variability was explained by SNP-smoking interactions provides compelling support for a role of these variants in predicting lung function.

\section{Comparisons to Previous Findings}

None of the most statistically significant SNPs have been investigated in published candidate gene association studies of lung function, and only 1 previous association study investigated other markers in genes represented in our top results. The variant genotype of a SNP in a glutathione synthesis gene, $G C L C$, was associated with an increased risk of COPD in a Chinese population [OR 1.8 (95\% CI: 1.0,3.3)][25]. This SNP (rs17883901) was included in our analyses, but no association was observed. The variant allele has a higher prevalence among Asians (13\%) than among African Americans (1\%) or Europeans (6\%), suggesting a potential reason for this discrepancy.

\section{The Role of Mitochondrial Proteins}

It is striking that among the genes identified to play a role in lung phenotypes, many encode enzymes located in the mitochondria; the mitochondrial genes identified include the $I D H$ genes (IDH3A, IDH3B, and IDH2) and PRDX5. To date, there are no studies of the role of mitochondrial function in relation to lung phenotypes at the population level, but results from animal and cell studies are informative. A recent series of experiments addressed the effect of cigarette smoke on lung epithelial cells. While systemic increases in biomarkers of oxidative stress occur with smoking, the high concentration of reactive oxygen species (ROS) in cigarette smoke are in the gaseous phase; these components likely assault the lining fluid and plasma membranes of epithelial cells, but cannot enter cells directly, which leaves the mechanism by which they contribute to systemic oxidative stress unclear. Lipophilic compounds in cigarette smoke are postulated to cross through the plasma membrane and induce mitochondrial overproduction of ROS, which, in turn, increases systemic (and local) oxidative stress [27]. In studies of mouse embryonic fibroblasts, oxidizing extracellular conditions induce mitochondrial overproduction of ROS, signaling an antioxidant response (through nuclear factor (erythroid-derived 2)-like 2, Nrf2). Embryonic fibroblasts from transgenic mice over-expressing TXNRD2 produced less 
intracellular ROS in oxidizing extracellular conditions, resulting in diminished Nrf2regulated antioxidant gene expression [28]. Also of interest, particulate matter, another inhalant associated with lung function decrements, induces mitochondrial oxidant overproduction, which leads to alveolar epithelial cell apoptosis. Overexpression of the gene encoding a cytoplasmic antioxidant enzyme (SOD1) prevented the excess ROS generation and subsequent cell death [29]. Taken together, these results support a key role for mitochondria and mitochondrial antioxidant enzymes in the lung and systemic response to cigarette smoke exposure. Specifically, the lipophilic portion of cigarette smoke and the oxidizing extracellular environment (the epithelial lining fluid after depletion of antioxidants resulting from direct contact with ROS in cigarette smoke) may induce an excess production of ROS in the mitochondria. Thus, variability in mitochondrial antioxidant enzyme expression or function as a result of sequence variation is expected to have significant effects on the oxidative burden in the lungs (and beyond).

\section{African vs. European Americans}

A larger proportion of statistically significant results were consistently observed in African Americans compared to European Americans. Potential explanations for this include the different phenotype distribution in the two populations and the different proportions exposed to cigarette smoking. Mean $\mathrm{ppFEV}_{1}$ was higher in African Americans, and the standard deviation was larger compared to European Americans; the mean $\mathrm{FEV}_{1} / \mathrm{FVC}$ ratio was also somewhat higher in African Americans, and the standard deviation was greater (Table 1). More variability in the phenotype could improve the ability to detect the genotypephenotype associations, but it is unlikely that distributional differences fully account for the differences observed by race. A much higher proportion of African Americans were current smokers (14\% compared to 5\% in European Americans), although their smoking history suggests a lower lifetime dose (27 vs. 34 pack years in African vs. European Americans, respectively). The higher proportion of participants who are current smokers suggests a greater burden of oxidative stress, thus increasing the chance of detecting a gene by smoking interaction. Ultimately, the same functional gene groups were identified in both African American and European American analyses (peroxidase activity and supply of reducing equivalents).

Several strengths of this work deserve mention. First, these analyses were conducted in a large, epidemiological cohort, a study design that is uniquely suited to investigate the genetics of complex diseases, especially when considering gene-environment interactions $[30,31]$. Other aspects of the design of the cohort study that are strengths include: the advanced age of the participants, which led to greater variability in the outcome as a result of both aging and environmental exposure; careful characterization of smoking history; a large proportion of African Americans to allow a stratified analysis (a relatively underdescribed population with respect to this research question); and high quality spirometry.

A few limitations should be considered when evaluating the results of this work. First, although our goal was to broadly consider genes encoding enzymes in known antioxidant pathways of importance in the lung, important antioxidant enzymes may have been omitted inadvertently, limiting our ability to make general statements about the role of all enzymes with antioxidant effect. Secondly, as redox balance and inflammation involve closely interrelated pathways, the focus on antioxidant enzymes alone is a somewhat artificial distinction, and further analysis of enzymes involved in inflammatory pathways would be of interest. Finally, although the Health ABC questionnaire data related to smoking habits is extensive, data on smoking may not always fully capture smoke exposure, as a result of both inadvertent and conscious errors in an individuals' responses as well as uncertainty in defining and capturing the most relevant aspects of smoking (for example, inhalation depth) for disease outcomes. Despite this source of uncertainty in these data, we were able to 
discover meaningful interactions between genotype and smoking parameters, suggesting that even more associations might be uncovered if smoking was more fully quantified.

In summary, this analysis provides evidence for a role of genetic variation in antioxidant enzymes in relation to lung function phenotypes important in predicting risk of COPD and the trajectory of aging. This work complements research conducted on dietary determinants of antioxidant capacity in that the genetic determinants of antioxidant capacity are not anticipated to be associated with lifestyle factors, and so are not subject to the same confounding bias that limits the interpretation of studies of diet. Of particular importance in these results are SNPs encoding members of the peroxiredoxin and isocitrate dehydrogenase gene families, suggesting that the function of peroxidases dependent on thioredoxin and the overall production of reducing equivalents are important in predicting lung outcomes, especially in the presence of oxidant challenge, and interventions that support these systems may yield beneficial results.

\section{Supplementary Material}

Refer to Web version on PubMed Central for supplementary material.

\section{Acknowledgments}

The authors acknowledge the consulting provided by Ms. Francoise Vermeylen, Cornell Statistical Consulting Unit, Cornell University.

A.R.B., P.A.C., S.K. designed research; A.R.B. and P.A.C. conducted research; A.R.B. and P.A.C. analyzed data; S.K., T.H., D.B., A.N., and B.M. provided essential materials; A.R.B., P.A.C., A.C. and S.K. wrote the paper. P.A.C. had primary responsibility for final content. All authors read and approved the final manuscript.

This project has been funded in part by NIH training grant T32 DK007158-31 (ARB), R01HL74104 (SBK), R01HL071022 (PAC), Genotyping services were provided (to PAC) by the Johns Hopkins University under federal contract number (N01-HV-48195) from the National Heart, Lung, and Blood Institute.

The Health ABC Study is supported by National Institute on Aging (NIA) contracts N01-AG-6-2101, N01AG-2103, N01-AG-6-2106, NIA grant R01-AG028050, and NINR grant R01-NR012459. This research was supported in part by the Intramural Research Program of the NIH, National Institute on Aging.

\section{ABBREVIATIONS}

$\begin{array}{ll}\text { COPD } & \text { chronic obstructive pulmonary disease } \\ \text { FEV }_{1} & \text { forced expiratory volume in the first second } \\ \text { FVC } & \text { forced vital capacity } \\ \text { ppFEV }_{1} & \text { percent of the } \text { FEV }_{1} \text { value predicted } \\ \text { CAT } & \text { Catalase } \\ \text { GGT1 } & \text { Gamma-glutamyl Transferase 1 } \\ \text { G6PD } & \text { Glucose-6-Phosphate Dehydrogenase } \\ \text { GCLC } & \text { Glutamate-cysteine ligase (catalytic subunit) } \\ \text { GCLM } & \text { Glutamate-cysteine ligase (modulatory subunit) } \\ \text { GLRX } & \text { Glutaredoxin } \\ \text { GLRX2 } & \text { Glutaredoxin 2 } \\ \text { GPX1 } & \text { Glutathione Peroxidase 1 }\end{array}$




\begin{tabular}{|c|c|}
\hline GPX2 & Glutathione Peroxidase 2 \\
\hline GPX3 & Glutathione Peroxidase 3 \\
\hline GPX4 & Glutathione Peroxidase 4 \\
\hline GPX7 & Glutathione Peroxidase 7 \\
\hline GSR & Glutathione Reductase \\
\hline GSTA1 & Glutathione S-Transferase A1 \\
\hline GSTA2 & Glutathione S-Transferase A2 \\
\hline GSTA3 & Glutathione S-Transferase A3 \\
\hline GSTA4 & Glutathione S-Transferase A4 \\
\hline GSTA5 & Glutathione S-Transferase A5 \\
\hline GSTK1 & Glutathione S-Transferase K1 \\
\hline GSTM2 & Glutathione S-Transferase M2 \\
\hline GSTM3 & Glutathione S-Transferase M3 \\
\hline GSTM4 & Glutathione S-Transferase M4 \\
\hline GSTO1 & Glutathione S-Transferase O1 \\
\hline GSTO2 & Glutathione S-Transferase O2 \\
\hline GSTP1 & Glutathione S-Transferase P1 \\
\hline GSTZ1 & Glutathione S-Transferase Z1 \\
\hline GSS & Glutathione Synthetase \\
\hline HMOX1 & Heme-Oxygenase 1 \\
\hline HMOX2 & Heme-Oxygenase 2 \\
\hline IDH1 & Isocitrate Dehydrogenase 1 \\
\hline IDH2 & Isocitrate Dehydrogenase 2 \\
\hline IDH3A & Isocitrate Dehydrogenase 3A \\
\hline IDH3B & Isocitrate Dehydrogenase 3B \\
\hline IDH3G & Isocitrate Dehydrogenase $3 \mathrm{G}$ \\
\hline mGST1 & Microsomal Glutathione S-Transferase 1 \\
\hline mGST2 & Microsomal Glutathione S-Transferase 2 \\
\hline mGST3 & Microsomal Glutathione S-Transferase 3 \\
\hline PRDX1 & Peroxiredoxin 1 \\
\hline PRDX2 & Peroxiredoxin 2 \\
\hline PRDX3 & Peroxiredoxin 3 \\
\hline PRDX4 & Peroxiredoxin 4 \\
\hline PRDX5 & Peroxiredoxin 5 \\
\hline PRDX6 & Peroxiredoxin 6 \\
\hline SEPP1 & Selenoprotein P 1 \\
\hline
\end{tabular}




$\begin{array}{ll}\text { SEPW1 } & \text { Selenoprotein W 1 } \\ \text { SOD1 } & \text { Superoxide Dismutase 1 } \\ \text { SOD2 } & \text { Superoxide Dismutase 2 } \\ \text { SOD3 } & \text { Superoxide Dismutase 3 } \\ \text { TXN } & \text { Thioredoxin 1 } \\ \text { TXN2 } & \text { Thioredoxin 2 } \\ \text { TXNRD1 } & \text { Thioredoxin Reductase 1 } \\ \text { TXNRD2 } & \text { Thioredoxin Reductase 2 } \\ \text { TXNRD3 } & \text { Thioredoxin Reductase 3 }\end{array}$

\section{References}

1. Minino AM, Arias E, Kochanek KD, Murphy SL, Smith BL. Deaths: final data for 2000. Natl Vital Stat Rep. 2002; 50(15):1-119. [PubMed: 12382630]

2. Global Initiative for Chronic Obstructive Lung D: Global Strategy for the Diagnosis, Management, and Prevention of Chronic Obstructive Pulmonary Disease. goldcopdcom. 2009

3. MacNee W. Pulmonary and Systemic Oxidant/Antioxidant Imbalance in Chronic Obstructive Pulmonary Disease. Proceedings of the American Thoracic Society. 2005; 2(1):50-60. [PubMed: 16113469]

4. Fletcher, CM. The Natural History of Chronic Bronchitis and Emphysema : An Eight-Year Study of Early Chronic Obstructive Lung Disease in Working Men in London. Oxford ; New York: Oxford University Press; 1976.

5. Hubert HB, Fabsitz RR, Feinleib M, Gwinn C. Genetic and environmental influences on pulmonary function in adult twins. Am Rev Respir Dis. 1982; 125(4):409-415. [PubMed: 7200340]

6. Redline S, Tishler PV, Lewitter FI, Tager IB, Munoz A, Speizer FE. Assessment of genetic and nongenetic influences on pulmonary function. A twin study. Am Rev Respir Dis. 1987; 135(1)

7. Wilk JB, Djousse L, Arnett DK, Rich SS, Province MA, Hunt SC, Crapo RO, Higgins M, Myers RH. Evidence for major genes influencing pulmonary function in the NHLBI family heart study. Genetic Epidemiology. 2000; 19(1):81-94. [PubMed: 10861898]

8. Lieberman J, Winter B, Sastre A. Alpha 1-antitrypsin Pi-types in 965 COPD patients. Chest. 1986; 89(3):370-373. [PubMed: 3485034]

9. Hancock DB, Eijgelsheim M, Wilk JB, Gharib SA, Loehr LR, Marciante KD, Franceschini N, van Durme YMTA, Chen Th, Barr RG, et al. Meta-analyses of genome-wide association studies identify multiple loci associated with pulmonary function. Nat Genet. 42(1):45-52. [PubMed: 20010835]

10. Repapi E, Sayers I, Wain LV, Burton PR, Johnson T, Obeidat Me, Zhao JH, Ramasamy A, Zhai G, Vitart V, et al. Genome-wide association study identifies five loci associated with lung function. Nat Genet. 42(1):36-44. [PubMed: 20010834]

11. Wilk JB, Chen Th, Gottlieb DJ, Walter RE, Nagle MW, Brandler BJ, Myers RH, Borecki IB, Silverman EK, Weiss ST, et al. A Genome-Wide Association Study of Pulmonary Function Measures in the Framingham Heart Study. PLoS Genet. 2009; 5(3) e1000429.

12. Bentley AR, Emrani P, Cassano PA. Genetic variation and gene expression in antioxidant related enzymes and risk of COPD: a systematic review. Thorax. 2008; 63(11):956-961. [PubMed: 18566111]

13. Gottlieb DJ, Wilk JB, Harmon M, Evans JC, Joost O, Levy D, O'Connor GT, Myers RH. Heritability of longitudinal change in lung function. The Framingham study. Am J Respir Crit Care Med. 2001; 164(9)

14. Tishler PV, Carey VJ, Reed T, Fabsitz RR. The role of genotype in determining the effects of cigarette smoking on pulmonary function. Genetic Epidemiology. 2002; 22(3):272-282. [PubMed: 11921087] 
15. Zhai G, Valdes AM, Cherkas L, Clement G, Strachan D, Spector TD. The Interaction of Genes and Smoking on Forced Expiratory Volume*. Chest. 2007; 132(6):1772-1777. [PubMed: 17989158]

16. Waterer GW, Wan JY, Kritchevsky SB, Wunderink RG, Satterfield S, Bauer DC, Newman AB, Taaffe DR, Jensen RL, Crapo RO, et al. Airflow Limitation is Underrecognized in WellFunctioning Older People. Journal of the American Geriatrics Society. 2001; 49(8):1032-1038. [PubMed: 11555063]

17. Hankinson JL, Odencrantz J, Fedan KB. Spirometric Reference Values from a Sample of the General U.S. Population. American Journal of Respiratory and Critical Care Medicine. 1999; 159(1):179-187. [PubMed: 9872837]

18. Naylor MG, Weiss ST, Lange C. Recommendations for using standardised phenotypes in genetic association studies. Human Genomics. 2009; 3(4):308-319. [PubMed: 19706362]

19. Benjamini Y, Hochberg Y. Controlling the False Discovery Rate: A Practical and Powerful Approach to Multiple Testing. Journal of the Royal Statistical Society. 1995; 57(1):289-300.

20. Barrett JC, Fry B, Maller J, Daly MJ. Haploview: analysis and visualization of LD and haplotype maps. Bioinformatics. 2005; 21(2):263-265. [PubMed: 15297300]

21. Pierrou S, Broberg P, O'Donnell RA, Pawlowski K, Virtala R, Lindqvist E, Richter A, Wilson SJ, Angco G, Moller S, et al. Expression of Genes Involved in Oxidative Stress Responses in Airway Epithelial Cells of Smokers with Chronic Obstructive Pulmonary Disease. American Journal of Respiratory and Critical Care Medicine. 2007; 175(6):577-586. [PubMed: 17158281]

22. Li L, Kaifu T, Obinata M, Takai T. Peroxiredoxin III-deficiency Sensitizes Macrophages to Oxidative Stress. Journal of Biochemistry. 2009; 145(4):425-427. [PubMed: 19155266]

23. In SK, Young SL, Young SB, Tae LH, Jeen-Woo P. Modulation of NADP<sup $>+</$ sup $>-$ dependent isocitrate dehydrogenase in aging. Redox Report. 2004; 9(5):271-277. [PubMed: 15606980]

24. Kil IS, Huh TL, Lee YS, Lee YM, Park JW. Regulation of replicative senescence by NADP+dependent isocitrate dehydrogenase. Free Radical Biology and Medicine. 2006; 40(1):110-119. [PubMed: 16337884]

25. Liu S, Li B, Zhou Y, Zhong N, Ran P. Genetic analysis of CC16, OGG1 and GCLC polymorphisms and susceptibility to COPD. Respirology. 2007; 12(1)

26. Hersh CP, Demeo DL, Lazarus R, Celedon JC, Raby BA, Benditt JO, Criner G, Make B, Martinez FJ, Scanlon PD, et al. Genetic association analysis of functional impairment in chronic obstructive pulmonary disease. Am J Respir Crit Care Med. 2006; 173(9)

27. van der Toorn M, Rezayat D, Kauffman HF, Bakker SJL, Gans ROB, Koeter GH, Choi AMK, van Oosterhout AJM, Slebos DJ. Lipid-soluble components in cigarette smoke induce mitochondrial production of reactive oxygen species in lung epithelial cells. AJP - Lung Cellular and Molecular Physiology. 2009; 297(1):L109-L114. [PubMed: 19411310]

28. Imhoff BR, Hansen JM. Extracellular redox status regulates Nrf2 activation through mitochondrial reactive oxygen species. Biochemical Journal. 2009; 424:491-500. [PubMed: 19778293]

29. Soberanes S, Urich D, Baker CM, Burgess Z, Chiarella SE, Bell EL, Ghio AJ, De Vizcaya-Ruiz A, Liu J, Ridge KM, et al. Mitochondrial Complex III-generated Oxidants Activate ASK1 and JNK to Induce Alveolar Epithelial Cell Death following Exposure to Particulate Matter Air Pollution. Journal of Biological Chemistry. 2009; 284(4):2176-2186. [PubMed: 19033436]

30. Davey Smith G, Ebrahim S. 'Mendelian randomization': can genetic epidemiology contribute to understanding environmental determinants of disease? Int J Epidemiol. 2003; 32(1):1-22. [PubMed: 12689998]

31. Manolio TA. Cohort studies and the genetics of complex disease. Nat Genet. 2009; 41(1):5-6. [PubMed: 19112455] 
Table 1

Characteristics of the Health, Aging, and Body Composition Study Participants Included in Analyses ${ }^{a}$

\begin{tabular}{|c|c|c|c|c|}
\hline \multirow[b]{2}{*}{ Covariate: } & \multicolumn{2}{|c|}{ Analysis of \% Predicted FEV $_{1}$} & \multicolumn{2}{|c|}{ Analysis of $\mathrm{FEV}_{1} / \mathrm{FVC}$} \\
\hline & $\begin{array}{c}\text { African } \\
\text { Americans } \\
\mathbf{n}=972\end{array}$ & $\begin{array}{c}\text { European } \\
\text { Americans } \\
\mathbf{n}=\mathbf{1 4 1 5}\end{array}$ & $\begin{array}{c}\text { African } \\
\text { Americans } \\
\mathbf{n}=\mathbf{8 5 5}\end{array}$ & $\begin{array}{c}\text { European } \\
\text { Americans } \\
\mathbf{n}=1335\end{array}$ \\
\hline Age, years & $73.3(2.9)$ & $73.7(2.8)$ & $73.3(2.9)$ & $73.7(2.9)$ \\
\hline Women $(\%)$ & $569(58.5)$ & $682(48.2)$ & $481(56.3)$ & $629(47.1)$ \\
\hline Memphis, TN site $(\%) b$ & $434(44.7)$ & $674(47.6)$ & $375(43.9)$ & $638(47.8)$ \\
\hline Former Smokers (\%) & $390(40.2)$ & $707(50.0)$ & $350(41.0)$ & $668(50.1)$ \\
\hline Current Smokers (\%) & $139(14.3)$ & $75(5.3)$ & $124(14.5)$ & $71(5.3)$ \\
\hline Pack-years & $27.4(23.9)$ & $34.3(30.9)$ & $27.7(23.9)$ & $34.2(30.8)$ \\
\hline \multicolumn{5}{|l|}{$\mathrm{FEV}_{1}, \mathrm{ml}$} \\
\hline Women & $1724(367)$ & $1946(379)$ & $1729(368)$ & $1959(376)$ \\
\hline Men & $2369(517)$ & $2759(531)$ & $2382(511)$ & $2767(533)$ \\
\hline$\%$ Predicted $\mathrm{FEV}_{1}$ & $99.4(21.4)$ & $95.5(16.9)$ & $99.8(21.3)$ & $95.9(16.9)$ \\
\hline $\mathrm{FEV}_{1} / \mathrm{FVC}(\%)$ & $77.0(7.4)$ & $75.9(6.1)$ & $76.0(6.6)$ & $75.1(5.8)$ \\
\hline
\end{tabular}

${ }^{a}$ Mean (SD) listed unless otherwise indicated; table columns refer to participants studied in the analysis of the listed phenotype

$b_{\text {vs. Pittsburgh, PA site. }}$ 


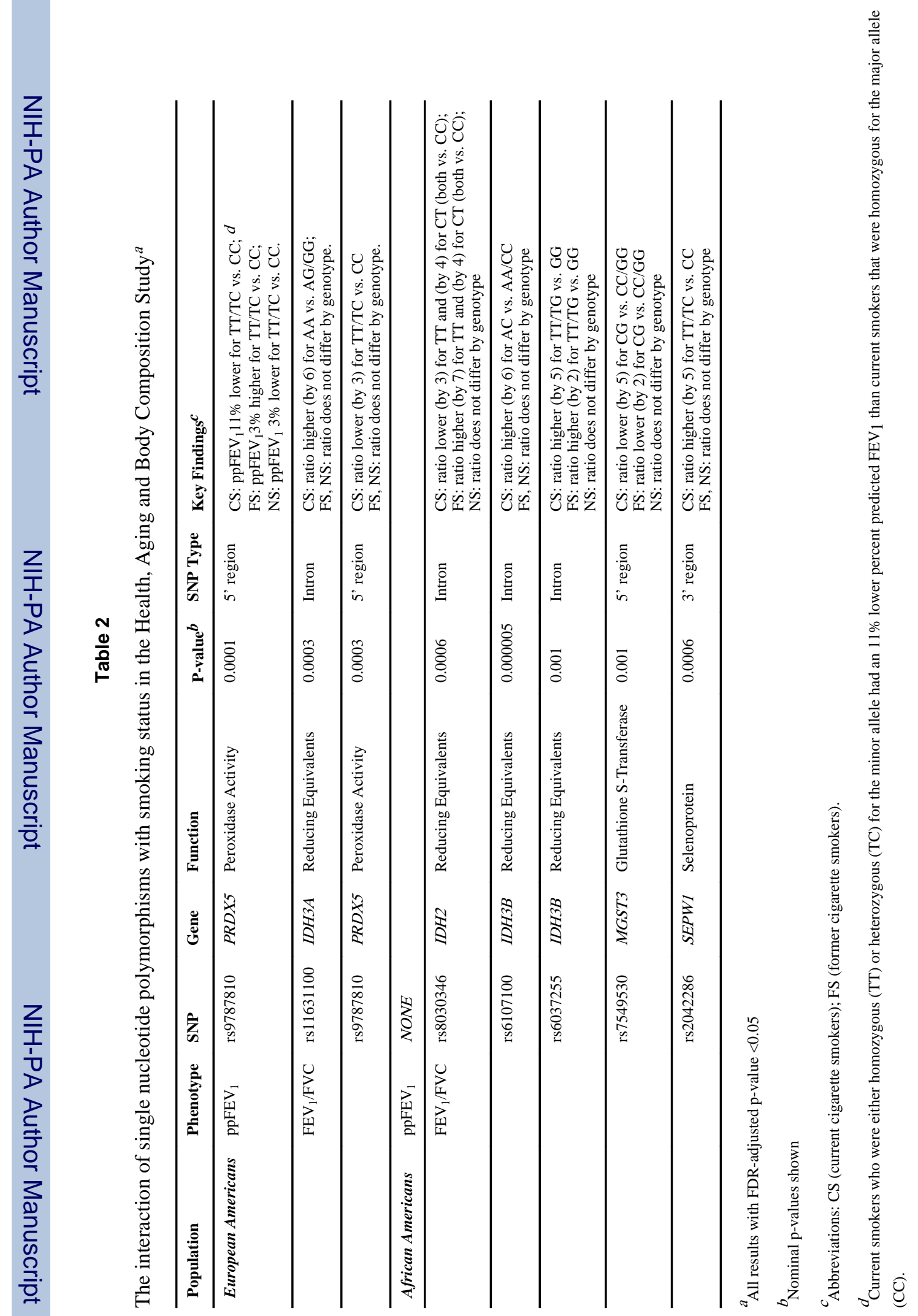




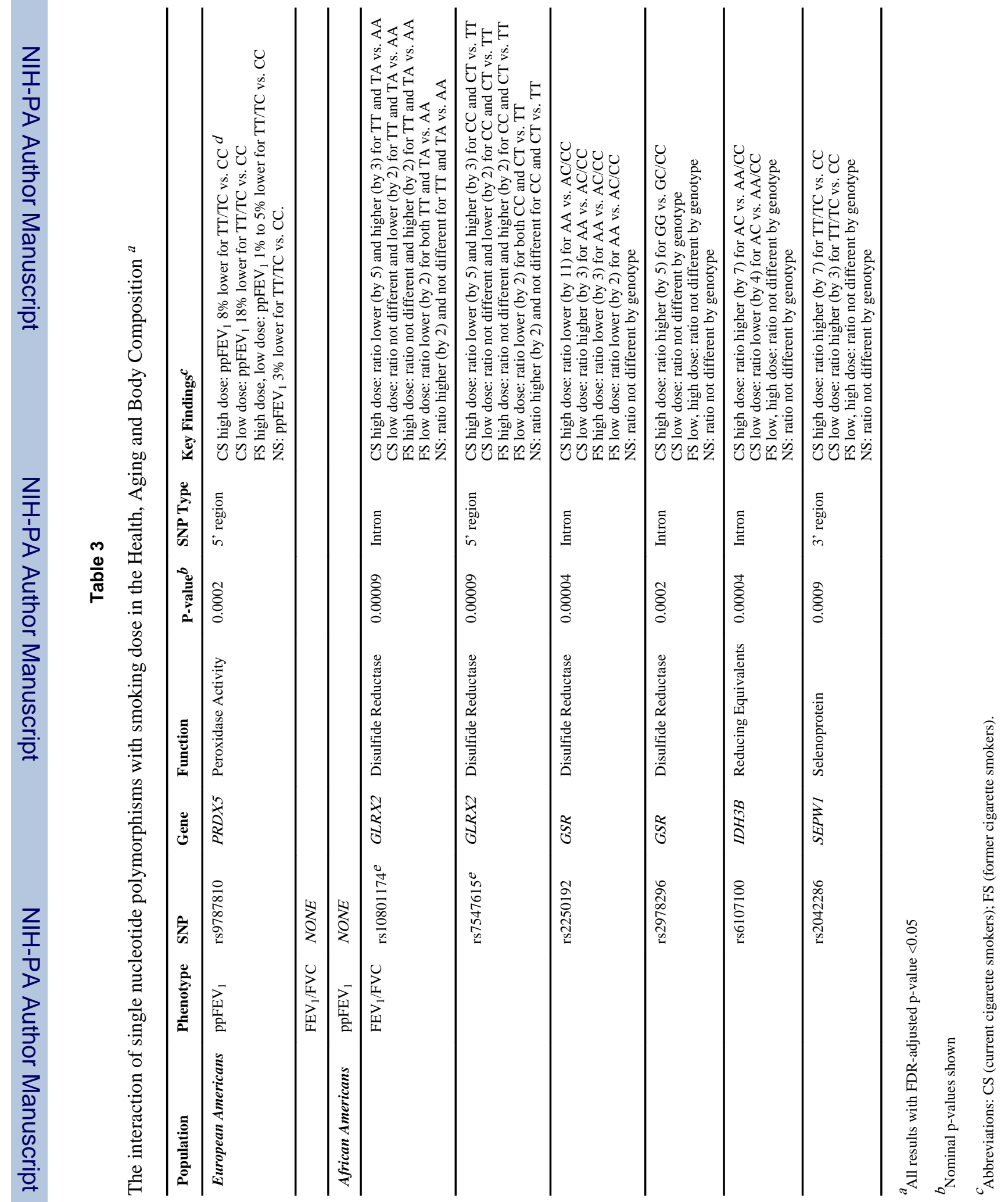


